\section{International Scientific Journal Theoretical \& Applied Science}

p-ISSN: 2308-4944 (print) $\quad$ e-ISSN: 2409-0085 (online)

Year: $2018 \quad$ Issue: $01 \quad$ Volume: 57

Published: $30.01 .2018 \quad$ http://T-Science.org

SECTION 33: Advertising technologies.

Creative. Innovations
D.O. Borduch

Institute of Service and Entrepreneurship (branch) of DSTU, ( Shakhty, Russia)

\section{A. V. Golovko}

graduate student, Institute of Entrepreneurship and Service sector (branch) DSTU, g. Shakhty

V.T. Prokhorov Doctor of technical sciences, professor, professor of the department "Designing, technology and design", ISOP (f) DGTU, g. Shakhty

P. N. Kozachenko candidate of chemical Sciences, head of Department "Natural Sciences" Institute of Service and Entrepreneurship

(branch) of DSTU, ( Shakhty, Russia)

N.V. Tihonova

Doctor of technical sciences, professor, professor of the department «Designing clothing and footwear», Research technological University

(Kazan, Tatarstan)

S.M. Zverev

JSC "Roslegprom" in city Moscow Professor, candidate of economic Sciences

(Moscow. Russia)

\title{
NEW IN THE EVALUATION OF THE EFFECTIVENESS OF INNOVATIVE TECHNOLOGICAL SOLUTIONS FOR THE PRODUCTION OF IMPORT-SUBSTITUTING SHOES (1 message)
}

\footnotetext{
Abstract: In the message 1 for analysis of a system of indicators for assessing the competitive potential of the enterprise and the importance of consumer properties of products, the authors propose to use a direct estimation method that allowed to obtain a generalized estimation of competitiveness, which on the one hand allows to show the degree of satisfaction with the product, and the degree of use of the competitive potential of the enterprise.

Key words: assessment of enterprise competitiveness and product innovation processes, profit, profitability, import substitution, assortment policy, competitive potential, target segment, the importance of consumer properties.

Language: Russian

Citation: Borduch DO, Golovko AV, Prokhorov VT, Kozachenko PN, Tihonova NV, Zverev SM (2018) NEW IN THE EVALUATION OF THE EFFECTIVENESS OF INNOVATIVE TECHNOLOGICAL SOLUTIONS FOR THE PRODUCTION OF IMPORT-SUBSTITUTING SHOES (1 message). ISJ Theoretical \& Applied Science, 01 (57): 358-372.

Soi: http://s-o-i.org/1.1/TAS-01-57-47 Doi: crossef https://dx.doi.org/10.15863/TAS.2018.01.57.47

UDC 685.34:335.74

НОВОЕ В ОЦЕНКЕ ЭФФЕКТИВНОСТИ ПРИНЯТЫХ ИННОВАЦИОННЫХ ТЕХНОЛОГИЧЕСКИХ РЕШЕНИЙ ДЛЯ ПРОИЗВОДСТВА ИМПОРТОЗАМЕЩАЕМОЙ ОБУВИ (Сообщение 1)
} 
Аннотация: в сообщении 1 для проведения анализа системы показателей по оценке конкурентного потенциала предприятия и значимости потребительских свойств продукции авторами предложено использовать метод непосредственной оценки, что позволило получить обобщенную оценку конкурентоспособности, которая с одной стороны позволяет показать степень удовлетворенности товаром, а с другой - степень использования конкурентного потенциала самого предприятия.

Ключевые слова: оценка конкурентоспособности предприятия и товара, инновационнье технологические процессы, прибыль, рентабельность, импортозамещение, ассортиментная политика, конкурентный потенцииал, целевой сегмент, значимость, потребительские свойства.

\section{Введение}

Характер новой конкуренции в

современной мировой экономике, обусловленный процессами глобализации, ставит перед производителями высокие требования как к повышению конкурентоспособности товаров, так и к конкурентоспособности предприятий. Повышение конкурентоспособности предприятий и отраслей является одним из важнейших направлений реального экономического роста, как в России, так и в регионах ЮФО и СКФО, что отражено в программном документе, а именно: в стратегии развития легкой промышленности России на период до 2025г.

В этой связи проблема конкурентоспособности отечественной обуви требует разработки концептуальных основ теоретико-методологических и практических рекомендаций, адекватных предстоящим изменениям в организационно-экономическом механизме функционирования всего промышленного комплекса страны.

\section{Основная часть}

В современных условиях рыночных отношений, конкурентной среды и непосредственного взаимодействия российских и зарубежных производителей решение проблемы сочетания государственных и рыночных механизмов управления конкурентоспособностью становится стратегическим ресурсом экономики регионов ЮФО и СКФО. В мировой экономике место ценовой конкурентоспособности заняла конкурентоспособность уровней качества, которая повысила свою актуальность с вхождением России в ВТО. Возрастание фактора качества результатов деятельности производства отечественной обуви в стратегии конкурентной борьбы на мировых рынках является долгосрочной тенденцией.

Особенно актуальна задача повышения конкурентоспособности для обувных предприятий, которые в силу внешних факторов (усиление конкуренции вследствие глобализации, мировой финансовый кризис) и внутренних (неэффективный менеджмент) утратили свои конкурентные позиции на внутреннем и внешнем рынках. В ответ на негативные процессы во внешней среде усиливаются процессы регионализации и создания различных сетевых структур, одной из которых является союз товаропроизводителей и государства.

Существуют три основных варианта концепции предприятия в развитой экономике: неоклассическая, агентская (акционерная) и партнерских отношений..

В концепции партнёрских отношений, или теории заинтересованных сторон, рассматривается зависимость действий фирмы от интересов широкого множества заинтересованных сторон, к числу которых относятся потребители, поставщики, акционеры, управляющие, работники и др. При этом каждый из партнёров имеет определенные права на контроль над предприятием, поэтому концепция предполагает необходимость принятия решений с учетом их интересов.

Теория стратегического управления является одним из самых непростых разделов управленческой науки. За достаточно короткий период существования, характеризовавшийся бурным развитием целого ряда концепций, она успела превратиться в самостоятельную научную дисциплину с собственной академической инфраструктурой. Важнейшим вопросом, на который должна дать ответ теория, является определение источников долгосрочной конкурентоспособности предприятий. Эти источники определяются стратегией предприятия и, соответственно, поднимают вопрос о ее природе.

Системная концепция предприятия может рассматриваться в качестве отправной точки для стратегического описания предприятий в настоящее время, поскольку ни одна из вышеперечисленных концепций «в чистом виде не представляет схемы для анализа, релевантной реальному положению и роли предприятия в любой экономике».

Недостаточная адекватность концепции партнёрских отношений предприятия, вытекает из того, что поведение промышленных предприятий определяется в наибольшей степени интересами лишь внутреннего высшего менеджмента и крупных собственников.

Следует, однако, отметить, что такая ситуация была характерна для 90-х годов прошлого столетия, но последние годы характеризуются переменами в этой сфере. 
Свидетельством тому является постепенное развитие и распространение в стране системы корпоративного управления, один из принципов которого напрямую подчеркивает роль заинтересованных лиц в управлении предприятием. Нельзя не отметить и повышение внимания к концепции социальной ответственности бизнеса в последнее время.

Одновременное сосуществование нескольких концепций, описывающих механизм принятия решений в управлении предприятием, связано с тем, что на разных этапах их деятельности возникают специфические задачи.

В частности, основными потребителями концепции заинтересованных сторон являются не все предприятия, а только те, которые заинтересованы в отношениях с широким кругом партнёров и управлении ими. Таким предприятиям теория заинтересованных сторон может предложить нестандартные подходы для решения их специфических задач.

Между предприятием и партнёрами существует определенные отношения, они могут быть различными, как конкурентными, так и сотрудническими. Партнёры могут существовать независимо друг от друга, а могут и взаимодействовать. Совокупность партнёров, которая приверженцами данной теории называется «коалицией участников бизнеса» или «коалицией влияния», представляет собой силу, которая непрерывно влияет на организацию, заставляя ее эволюционировать, видоизменяться и корректироваться.

В современной трактовке теории заинтересованных сторон партнёры рассматриваются не просто как группы и лица, затрагиваемые деятельностью организации, но как вкладчики определенного типа ресурса. Заинтересованные стороны поставляют предприятию необходимые для его деятельности ресурсы, потому что его деятельность позволяет удовлетворять его запросы. При этом удовлетворение запросов партнёра есть не что иное, как получение им от организации ресурсов. Таким образом, отношения между предприятием и его партнёрами выстраиваются вокруг ресурсного обмена, поскольку каждый стремится создать собственную ресурсную базу, которая наилучшим образом соответствовала бы целям партнёров.

Партнёров предприятия можно разделить на две группы: внешние и внутренние. К внешним партнёрам относятся: покупатели, поставщики, конкуренты, государственные учреждения и организации, органы муниципального, регионального и федерального управления, финансовые посредники.

Покупатели. Стратегия и тактика работы с важными покупателями включает в себя совместные заседания для определения движущих сил изменения бизнеса, обоюдные усилия по разработке продукции и рынка, увеличению коммуникативных связей, использованию общих площадей и совместные программы обучения и обслуживания. Укрепление связей с покупателями часто дает значительную выгоду.

Поставщики. Многие предприятия привлекают стратегически важных поставщиков к процессу разработки продукции и производству. Большинство предприятий, которые используют метод «точно в срок», когда комплектующие, производимые поставщиками, подаются непосредственно в сборочные цеха, минуя склад, включают поставщиков в свои внутренние процессы.

Конкуренты. Конкуренты являются сложной проблемой, поскольку часто бывает так, что в интересах одного конкурента заставить дрогнуть другого. Однако конкуренты объединяют усилия для борьбы с угрозой появления инновационных продуктов третьей стороны, для успешного прохождения жизненных циклов и для скачка вперед на основе новых технологий. Конкурирующие организации формируют союзы для ускорения технологического прогресса и разработки новой продукции, для выхода на новые или зарубежные рынки, для поиска широкого круга новых возможностей. Иногда сотрудничество определяется необходимостью выработки общих стандартов, созданием общей системы сервисного обслуживания и т.д.

Государственные учреждения и организации. Инновационные центры, государственно-частные предприятия и правительственные органы управления имеют много общих целей, среди которых создание благоприятных условий для международной торговли, стабильных рыночных условий, сдерживания инфляции, успешной экономики, производства необходимых товаров и услуг. Партнерство правительства и бизнеса (государственно-частное партнерство) широко практикуется в зарубежных странах, где правительства зачастую играют более активную роль и экономическом развитии страны.

Органы регионального и муниципального управления. Хорошие отношения с местными и региональными ветвями власти могут привести к выгодному для предприятий местному регулированию или снижению местных налогов. Поэтому, наиболее дальновидные руководители коммерческих организаций тратят определенные средства для помощи региональным и муниципальным ветвям властям в их усилиях решения местных проблем. Спонсорство для поддержки местных социальных программ, помощь общеобразовательным школам, 
учреждениям культуры, здравоохранения, правопорядка и т.д. позволяют достигать взаимопонимания и поддержки со стороны таких влиятельных для малого и среднего бизнеса партнёров, как органы регионального и муниципального управления.

Финансовые посредники - это совокупность множества организаций, которое включает, в частности, банки, юридические конторы, брокерские фирмы, консультантов по капиталовложениям, пенсионные фонды, компании с взаимными фондами, а также другие организации или участие отдельных граждан, которые могут быть заинтересованы в инвестировании средств в предприятие. Доверие особенно важно в общении с кредиторами. Раскрытие финансовой информации помогает установить доверие, так же как и своевременные платежи. Пытаясь наладить свои отношения с кредиторами и установить отношения доверия, многие предприятия приглашают их представителей в свои советы директоров.

В настоящее время отсутствует общепринятая методика оценки конкурентоспособности предприятия. Обзор существующих подходов к оценке конкурентоспособности предприятия позволил объединить их в следующие группы.

\begin{tabular}{cccc}
\multicolumn{1}{c}{ Первая } & группа & учёных & экономистов \\
включает & подход & $\kappa$ & определению
\end{tabular}
конкурентоспособности предприятий, основанный на выявлении конкурентных преимуществ. Данный подход возник с появлением стратегического планирования и развитием теории конкуренции. Он позволяет провести анализ достигаемых конкурентных преимуществ предприятия, но не дает точного количественного выражения результатов оценки и поэтому не может использоваться для сравнительного анализа конкурентоспособности предприятий, анализа выполнения плана повышения конкурентоспособности, динамики конкурентоспособности предприятий.

Вторая группа ученых-экономистов предлагает оценку конкурентоспособности с использованием многоугольных профилей. Она базируется на построении векторов конкурентоспособности по факторам: концепция, качество, цена, финансы, торговля, послепродажный сервис, внешняя политика, предпродажная подготовка. Однако авторы не уточняют, как можно оценить такие факторы, как концепция, внешняя политика, предпродажная подготовка и др., совместив их в одно целое.

Третья группа учёных-экономистов предлагают рейтинговую оценку конкурентоспособности предприятия на основе следующих факторов: товар, ассортимент, цена, имидж, сервис, упаковка (оформление), объемы продаж, сегмент рынка, поставка и сбытовая политика, реклама и стимулирование спроса, то есть с расчётом коэффициента эффективности инновационных технологических решений. Достоинством такого подхода э в том, что он, по сути, оценивает не только маркетинговую деятельность предприятия, но и учитывает другие важные ресурсы потенциала предприятия (инновации, менеджмент, финансы и др.). В предлагаемом авторами подходе получается более весомая сумма факторов, взаимная весомость которых учитывается в партнёрских отношениях.

Четвертая группа ученых-экономистов предлагает оценивать конкурентоспособность предприятия на основе произведения индекса по товарной массе и индекса эффективности объекта. Достоинством этого подхода является тот факт, что это более весомый подход к оценке, поскольку он учитывает такие важные факторы, определяющие конкурентные преимущества предприятия, как уровень организации и осуществлении маркетинга на предприятии, финансы, экспортный потенциал. Кроме того, большинство авторов считают важным разработку методики определения коэффициент эффективности производителя, его конкурентоспособность, что и будет формировать эффективность этих самых партнёрских отношений.

К четвертому подходу можно отнести и метод, предложенный Фатхудиновым Р.А., который предлагает оценивать конкурентоспособность предприятия как взвешенную сумму конкурентоспособностей основных товаров предприятия на различных рынках с учетом значимости рынков. Но этот подход не совсем справедлив, т.к. во-первых, конкурентоспособность организации отождествляется с конкурентоспособностью товара (это разные понятия), во-вторых, он предлагает ввести значимость зарубежных рынков вдвое большую, чем значимость национальных рынков. В-третьих, метод оценки Фатхутдинова Р.А. не учитывает других важных факторов влияния на конкурентоспособность маркетинг, финансы, инновации, менеджмент, кадры.

Пятая группа учёных-экономистов предлагает подход, основанный на взвешенной оценке факторов конкурентоспособности предприятия. Интегральный показатель конкурентоспособности предприятия определяется по правилам линейной свертки (оценка факторов конкурентоспособности отдельных сторон деятельности предприятия умножается на весомость отдельных факторов в общей сумме), то есть что-то близкое тому, что предлагается авторами данной статьи, а именно, 


\begin{tabular}{|c|c|c|c|c|c|c|}
\hline Impact Factor: & $\begin{array}{l}\text { ISRA (India) } \\
\text { ISI (Dubai, UAE } \\
\text { GIF (Australia) } \\
\text { JIF }\end{array}$ & $\begin{array}{r}=1.344 \\
=0.829 \\
=0.564 \\
=1.500\end{array}$ & $\begin{array}{l}\text { SIS (USA) } \\
\text { PИНЦ (Russia) } \\
\text { ESJI (KZ) } \\
\text { SJIF (Morocco }\end{array}$ & $\begin{array}{l}=0.912 \\
=0.207 \\
=4.102 \\
=\mathbf{2 . 0 3 1}\end{array}$ & $\begin{array}{l}\text { ICV (Poland) } \\
\text { PIF (India) } \\
\text { IBI (India) }\end{array}$ & $\begin{array}{l}=6.630 \\
=1.940 \\
=4.260\end{array}$ \\
\hline
\end{tabular}

расчёт коэффициента эффективности инновационных технологических решений.

Итак, анализ теоретико-методологических аспектов конкурентоспособности предприятий выявил множество методик оценки самой конкурентоспособности предприятий.

В этой связи успешная деятельность предприятия будет определяться степенью удовлетворенности интересов заинтересованных лиц, поэтому для повышения конкурентоспособности и эффективности деятельности предприятие должно учитывать не только свои интересы, но и интересы заинтересованных сторон, своих партнёров по бизнесу.

В теории заинтересованных сторон применяется термин партнёрских отношений, который формирует условия для обеспечения эффективности результатов деятельности предприятия.

Развивающимся малым и средним предприятием в качестве инструмента конкурентной борьбы необходимо формировать систему маркетинговых взаимоотношений с партнёрами, систему, основанную на взаимовыгодном долгосрочном сотрудничестве, позволяющую сокращать время на принятие эффективных коммерческих решений.

Поэтому, с учетом рассмотренных методологических основ конкурентоспособности предприятия, предлагается методика оценки и анализа конкурентоспособности обувных предприятий, работающих в регионах ЮФО и СКФО, на основе теории заинтересованных сторон. .а именно, ЗАО «Донобувь»(г. Ростов - на Дону) и ООО «Леонов»(г. Ростов -на Дону),являющиеся конкурентами по производству мужской обуви.

С учетом проведенного анализа системы показателей оценки конкурентного потенциала предприятия, оценку этими предприятиям дадим по системе показателей оценки факторов конкурентоспособности предприятий, предложенной выше. Первый важный фактор конкурентоспособности предприятия конкурентоспособность товара.

Все расчеты сводятся к осуществлению последовательных этапов.

1 этап. Расчет значимости потребительских свойств в оценке конкурентоспособности обуви. Значимость потребительских свойств предлагается рассчитывать с использованием метода непосредственной оценки. Для этого предлагается анкета, в которой каждому респонденту необходимо определить важность, по его мнению, каждого потребительского свойства товара в пределах используемой шкалы. Коэффициент весомости рассчитывается отдельно по каждому анализируемому сегменту по следующей формуле (1):

$$
\alpha_{\mathrm{j}}=\frac{O_{c p}}{\sum_{\mathrm{j}=1}^{\mathrm{n}} \mathrm{O}_{\mathrm{cpj}}}
$$

где $\quad \alpha_{j}-$ коэффициент значимости i-ого свойства,

$O_{c p \text { j }}$ - оценка і-ого свойства, данная ј ым респондентом, балл,

$\mathrm{n}$ - число оцениваемых свойств товара,

Условием правильности расчета коэффициента значимостей является следующие: $\mathrm{a}_{\mathrm{i}}=1$.

На этом этапе проводится расчет значимости потребительских свойств в оценке конкурентоспособности мужской обуви. Было опрошено 50 респондентов, которые оценили в баллах все потребительские свойства. Результаты оценки представлены в таблице.

Для этого про сегментируем рынок и выберем целевые сегменты (таблица 1).

Наибольшее число потребителей (76\%) относится к числу обычных покупателей («умеренные»). Половина отвечавших имеют средний уровень доходов $(50 \%)$, хотя уровень доходов «ниже среднего» (38\%) более чем в три раза превышает число тех, у кого доход «выше среднего» (соответственно 38\% и 12\%).

Характеристика целевых сегментов мужской обуви.

Таблица 1

\begin{tabular}{|c|c|c|c|}
\hline \multirow[t]{2}{*}{ Название критериев } & \multicolumn{2}{|c|}{ количество } & \multirow[t]{2}{*}{ Характеристики сегментов } \\
\hline & $\%$ & человек & \\
\hline Отношение к моде & $\begin{array}{l}14 \\
76 \\
10 \\
\end{array}$ & $\begin{array}{l}7 \\
38 \\
5 \\
\end{array}$ & $\begin{array}{l}\text { «авангардисты» } \\
\text { «умеренные» } \\
\text { «консерваторы» }\end{array}$ \\
\hline Возраст & $\begin{array}{l}62 \\
26 \\
10 \\
2\end{array}$ & $\begin{array}{l}31 \\
13 \\
5 \\
1\end{array}$ & $\begin{array}{l}\text { «молодежная группа» } \\
\text { «средний возраст» } \\
\text { «старший возраст» } \\
\text { «почтенный возраст» }\end{array}$ \\
\hline
\end{tabular}




\begin{tabular}{l|lr|ll|ll} 
& ISRA (India) & $=\mathbf{1 . 3 4 4}$ & SIS (USA) & $=\mathbf{0 . 9 1 2}$ & ICV (Poland) & $=\mathbf{6 . 6 3 0}$ \\
Impact Factor: & ISI (Dubai, UAE) $=\mathbf{0 . 8 2 9}$ & PUHЦ (Russia) $=\mathbf{0 . 2 0 7}$ & PIF (India) & $=\mathbf{1 . 9 4 0}$ \\
& GIF (Australia) & $\mathbf{0 . 5 6 4}$ & ESJI (KZ) & $=4.102$ & IBI (India) & $=\mathbf{4 . 2 6 0}$ \\
& JIF & $=\mathbf{1 . 5 0 0}$ & SJIF (Morocco) & $=\mathbf{2 . 0 3 1}$ & & \\
\hline
\end{tabular}

\begin{tabular}{|l|l|l|l|}
\hline Уровень доходов & 38 & 19 & «ниже среднего» \\
& 50 & 25 & «средний» \\
\hline Социальный статус & 12 & 6 & «выше среднего» \\
& 38 & 19 & «низкий социальный статус» \\
& 38 & 19 & «средний социальный статус» \\
\hline
\end{tabular}

Проведём группировку анкет по критерию «отношение к моде», так как этот критерий является определяющим в потребительских предпочтениях (сегментообразующим). Все остальные критерии (возраст, уровень доходов, социальный статус) в нём.

По результатам группировки анкет строим профили сегментов (таблица 2).

Составленная таблица показывает, что модную продукцию предпочитают респонденты, которые относятся к числу обычных покупателей («умеренные») младшей группы, так как это подчеркивает их индивидуальность, хотя уровень дохода у них ниже среднего.

На основании данных можно рассчитать значимость потребительских свойств в оценке конкурентоспособности товара на основе ответов «авангардистов» (таблицы 3 ).

Профили сегментов потребителей.

Таблица 2

\begin{tabular}{|c|c|c|c|}
\hline Признаки & \multicolumn{3}{|c|}{ сегменты } \\
\hline $\begin{array}{c}\text { отношение к } \\
\text { моде }\end{array}$ & «авангардисты» & «умеренные» & «консерваторы» \\
\hline $\begin{array}{c}\text { возрастная } \\
\text { группа }\end{array}$ & $\begin{array}{l}\text { Младшая - } 5 \\
\text { Средняя - } 2\end{array}$ & $\begin{array}{c}\text { Младшая - } 26 \\
\text { Средняя - } 10 \\
\text { Старшая - } 2 \\
\end{array}$ & $\begin{array}{c}\text { Старшая - } 3 \\
\text { Почтенная - } 2\end{array}$ \\
\hline уровень доходов & $\begin{array}{c}\text { Средний - } 3 \\
\text { Выше среднего - } 4\end{array}$ & $\begin{array}{l}\text { Ниже среднего - } 16 \\
\text { Средний - } 20 \\
\text { Выше среднего - } 2\end{array}$ & $\begin{array}{c}\text { Ниже среднего - } 4 \\
\text { Средний - } 1\end{array}$ \\
\hline искомые выгоды & $\begin{array}{c}\text { Индивидуальность - } \\
6 \\
\text { Высокое качество } \\
\text { товара - } 1\end{array}$ & $\begin{array}{c}\text { Индивидуальность - } 13 \\
\text { Высокое качество товара - } \\
17 \\
\text { Низкая цена - } 8\end{array}$ & $\begin{array}{c}\text { Низкая цена }-4 \\
\text { Высокое качество } \\
\text { товара - } 1\end{array}$ \\
\hline
\end{tabular}

Таблица 3

Расчет значимости потребительских свойств в оценке конкурентоспособности мужской обуви на основе ответов «авангардистов».

\begin{tabular}{|c|c|c|c|c|c|c|c|c|}
\hline 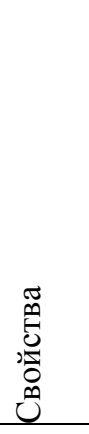 & 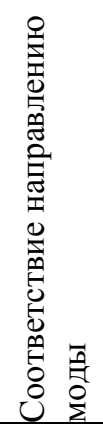 & 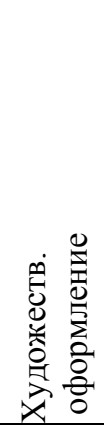 & 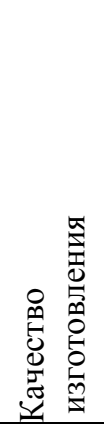 & 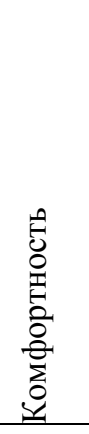 & 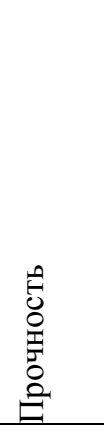 & 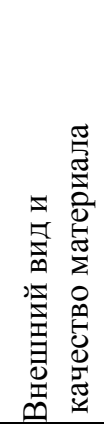 & 䔍 & 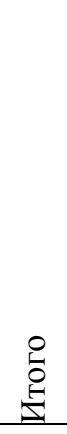 \\
\hline & 34 & 32 & 30 & 31 & 22 & 28 & 29 & 206 \\
\hline $\mathrm{A}_{\mathrm{ai}}$ & 0,165 & 0,155 & 0,146 & 0,15 & 0,107 & 0,136 & 0,141 & 1 \\
\hline
\end{tabular}

Рассчитаем потребительских значимость конкурентоспособности товара на основе ответов «умеренных» (таблицы 4). 


\begin{tabular}{|c|c|c|c|c|c|c|}
\hline Impact Factor: & $\begin{array}{l}\text { ISRA (India) } \\
\text { ISI (Dubai, UAE } \\
\text { GIF (Australia) } \\
\text { JIF }\end{array}$ & $\begin{array}{r}=1.344 \\
=0.829 \\
=0.564 \\
=1.500\end{array}$ & $\begin{array}{l}\text { SIS (USA) } \\
\text { PИHЦ (Russia) } \\
\text { ESJI (KZ) } \\
\text { SJIF (Morocco) }\end{array}$ & $\begin{array}{l}=0.912 \\
=0.207 \\
=4.102 \\
=2.031\end{array}$ & $\begin{array}{l}\text { ICV (Poland) } \\
\text { PIF (India) } \\
\text { IBI (India) }\end{array}$ & $\begin{array}{l}=6.630 \\
=1.940 \\
=4.260\end{array}$ \\
\hline
\end{tabular}

Таблица 4

Расчет значимости потребительских свойств в оценке конкурентоспособности мужской обуви на основе ответов «умеренных».

\begin{tabular}{|c|c|c|c|c|c|c|c|c|}
\hline 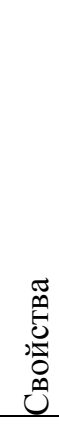 & 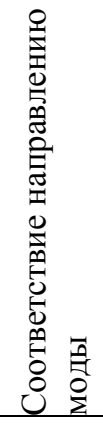 & 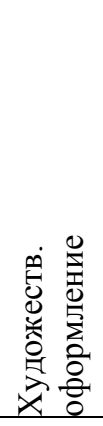 & 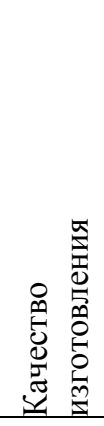 & 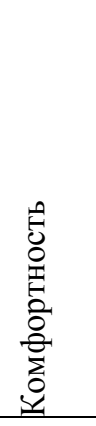 & 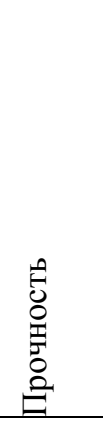 & 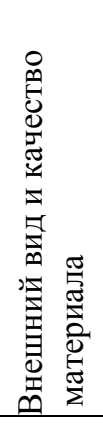 & 䔍 & $\begin{array}{l}0 \\
\stackrel{0}{E} \\
\end{array}$ \\
\hline & 154 & 171 & 149 & 169 & 130 & 159 & 167 & 1099 \\
\hline $\mathrm{A}_{\mathrm{ai}}$ & 0,14 & 0,156 & 0,136 & 0,154 & 0,118 & 0,145 & 0,152 & 1 \\
\hline
\end{tabular}

Рассчитаем значимость потребительских свойств в оценке конкурентоспособности товара на основе ответов «консерваторов» (таблицы 5).

Таблица 5

Расчет значимости потребительских свойств в оценке конкурентоспособности мужской обуви на основе ответов «консерваторов».

\begin{tabular}{|c|c|c|c|c|c|c|c|c|}
\hline 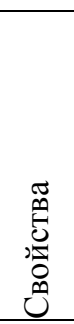 & 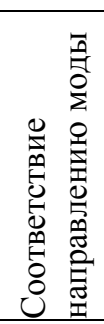 & 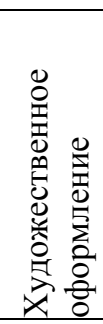 & 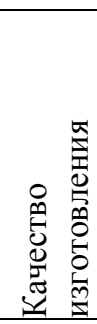 & 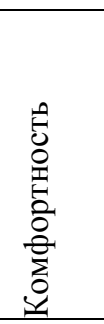 & 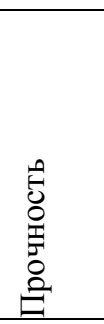 & 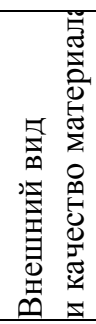 & 导 & $\begin{array}{l}\stackrel{0}{0} \\
\stackrel{g}{\Xi}\end{array}$ \\
\hline & 10 & 17 & 19 & 18 & 21 & 20 & 23 & 128 \\
\hline $\mathrm{A}_{\mathrm{ai}}$ & 0,08 & 0,133 & 0,148 & 0,141 & 0,162 & 0,156 & 0,18 & 1 \\
\hline
\end{tabular}

2 этап. Отбор экспертов. Формирование экспертной группы осуществляется на основе их самооценки, путем заполнения анкеты. В качестве экспертов выступают работники торговли (товароведы, продавцы). Всего опрашивалось 10 экспертов. Из них в группу отбирается 5-7 человек, получивших максимальную сумму оценок по всем направлениям. Им было задано по три вопроса, из них наиболее высокие оценки по трем направлениям (9 баллов) получили четыре эксперта. Они и были привлечены для исследования конкурентоспособности мужской обуви. Затем экспертам было предложено оценить свойства мужской обуви по пятибалльной шкале.
3 этап. Выбор товаров-конкурентов (ассортиментного ряда) для сравнения конкурентоспособности выбирается продукция тех производителей, которые, во-первых, обслуживают аналогичные сегменты, во-вторых, пользуются устойчивым спросом на рынке.

4 этап. Оценка потребительских свойств мужской обуви (ассортиментного ряда) целевыми сегментами.

Для сравнения потребительских свойств ассортиментных групп различных производителей также использовали анкету. Респондентам необходимо дать оценку в баллах по пятибалльной шкале каждому потребительскому свойству сравниваемых групп товаров. Шкала оценки указывается в анкете и сведится в итоговую таблицу 6. 


\begin{tabular}{l|lr|ll|ll} 
& ISRA (India) & $=\mathbf{1 . 3 4 4}$ & SIS (USA) & $=\mathbf{0 . 9 1 2}$ & ICV (Poland) & $=\mathbf{6 . 6 3 0}$ \\
Impact Factor: & ISI (Dubai, UAE) $=\mathbf{0 . 8 2 9}$ & PUHL (Russia) $=\mathbf{0 . 2 0 7}$ & PIF (India) & $=\mathbf{1 . 9 4 0}$ \\
& GIF (Australia) & $=\mathbf{0 . 5 6 4}$ & ESJI (KZ) & $=4.102$ & IBI (India) & $=\mathbf{4 . 2 6 0}$ \\
& JIF & $=\mathbf{1 . 5 0 0}$ & SJIF (Morocco) & $=\mathbf{2 . 0 3 1}$ & & \\
\hline
\end{tabular}

Оценка потребительских свойств мужской обуви.

Таблица 6

\begin{tabular}{|c|c|c|c|c|c|c|c|}
\hline 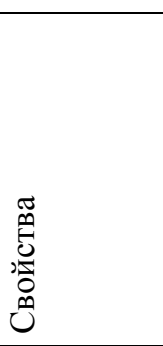 & 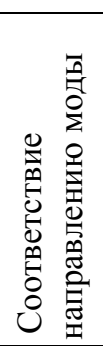 & 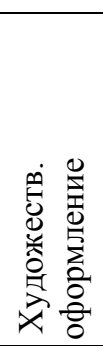 & 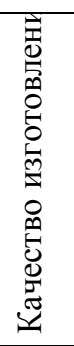 & 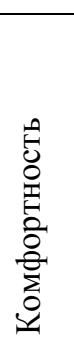 & 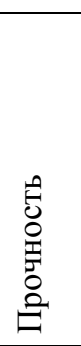 & 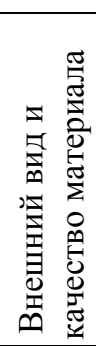 & 㺃 \\
\hline Донобувь & 3,33 & 3,17 & 3,67 & 3,42 & 3,75 & 3,83 & 3,33 \\
\hline Леонов & 3,27 & 2.49 & 3.37 & 2.84 & 3,29 & 3,31 & 2.96 \\
\hline $\begin{array}{l}\text { Среднее } \\
\text { значение }\end{array}$ & 3,3 & 2,83 & 3,52 & 3,13 & 3,52 & 3,57 & 3,145 \\
\hline
\end{tabular}

5 этап. Определение средней оценки по потребительским свойствам для каждого сегмента. Сгруппированные по целевым сегментам анкеты обрабатываются следующим образом.
По каждому потребительскому свойству находится среднее значение оценки в баллах как средняя арифметическая по всем респондентам данной целевой группы. Данные сведем в таблицу 7.

Таблица 7

Средняя оценка мужской обуви по потребительским свойствам «авангардистов», «консерваторов»

\begin{tabular}{|c|c|c|c|c|c|c|c|}
\hline 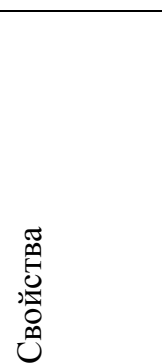 & 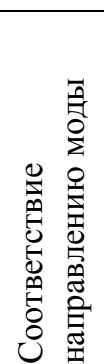 & 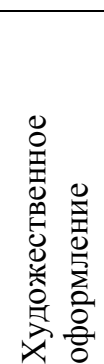 & 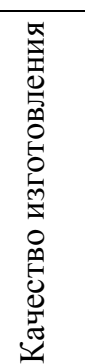 & 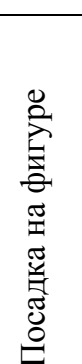 & 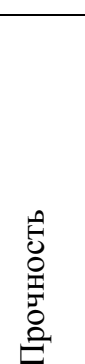 & 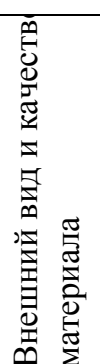 & 䄈 \\
\hline \multicolumn{8}{|c|}{ «Авангардисты» } \\
\hline Донобувь & 3,33 & 3,17 & 3,67 & 3,42 & 3,75 & 3,83 & 3,33 \\
\hline \multicolumn{8}{|c|}{ «Консерваторы» } \\
\hline Леонов & 3,27 & 2,49 & 3,37 & 2,84 & 3,29 & 3,31 & 2,96 \\
\hline $\begin{array}{l}\text { Среднее } \\
\text { значение }\end{array}$ & 3,3 & 2,83 & 3,52 & 3,13 & 3,52 & 3,57 & 3,14 \\
\hline
\end{tabular}

6 этап. Расчет суммарной оценки конкурентоспособности товара.

Уровень конкурентоспособности товара по оценке целевого сегмента определяют по следующей формуле (2).

$$
K=\sum_{\mathrm{i}=1}^{\mathrm{m}} \alpha_{\mathrm{i}} \cdot O_{c p}
$$

где К - суммарная оценка абсолютной конкурентоспособности товара, данная целевым сегментом, балл,

$$
\alpha_{\mathrm{i}} \text { - значимость i- го потребительского }
$$

свойства для целевого сегмента,
$O_{c p}-$ средняя оценка і- го потребительского свойства, данная целевым сегментом, балл,

$\mathrm{m}$ - количество сравниваемых потребительских свойств.

Таким образом, суммарная оценка конкурентоспособности одного и того же товара, данная представителями разных сегментов, будет различаться. Для принятия управленческих решений по конкурентоспособности, в анализе используются результаты оценки конкурентоспособности мужской обуви, которые проставили представители целевого сегмента.

Максимальная оценка коэффициента товара -5 баллов. 


\begin{tabular}{l|lr|ll|ll} 
& ISRA (India) & $=\mathbf{1 . 3 4 4}$ & SIS (USA) & $=\mathbf{0 . 9 1 2}$ & ICV (Poland) & $=\mathbf{6 . 6 3 0}$ \\
Impact Factor: & ISI (Dubai, UAE) $=\mathbf{0 . 8 2 9}$ & PUHЦ (Russia) $=\mathbf{0 . 2 0 7}$ & PIF (India) & $=\mathbf{1 . 9 4 0}$ \\
& GIF (Australia) & $\mathbf{0 . 5 6 4}$ & ESJI (KZ) & $=4.102$ & IBI (India) & $=\mathbf{4 . 2 6 0}$ \\
& JIF & $=\mathbf{1 . 5 0 0}$ & SJIF (Morocco) & $=\mathbf{2 . 0 3 1}$ & & \\
\hline
\end{tabular}

Фактически уровень конкурентоспособности может быть ниже максимальной оценки.

Рассчитаем конкурентоспособность по предприятиям с учетом определенной выше значимости. Полученные данные занесем в таблицу 8.

Анализ конкурентоспособности мужской обуви.

Таблица 8

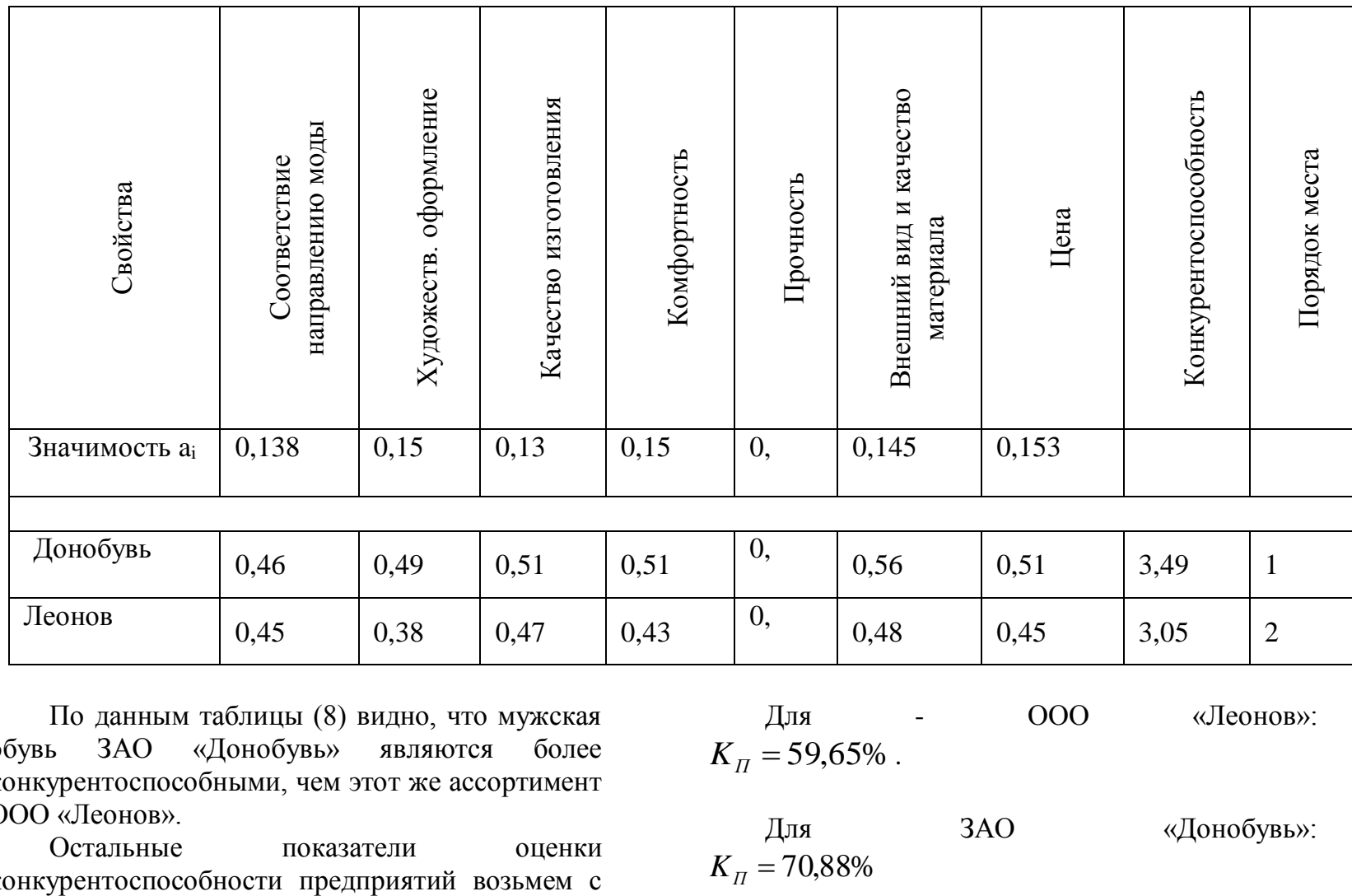

конкурентоспособности предприятий возьмем с технико-экономических показателей предприятий, данных бухгалтерского баланса.

Рассчитаем безразмерные оценки показателей конкурентоспособности предприятий и сведем все в таблицу 9.

Для перевода размерных оценок показателей в безразмерные предлагается использовать индексный метод. Который был рассмотрен выше.

Итак, на основании представленных данных рассчитаем обобщающие показатели конкурентоспособности исследуемых предприятий с использованием формулы (3).
Как видно по шкале оценки качественного уровня конкурентоспособности ООО «Леонов» и ЗАО «Донобувь» имеют средний уровень конкурентоспособности на рынке обувных предприятий ЮФО и СКФО.

Проведем анализ второго по значимости потенциала конкурентоспособности предприятий - эффективность маркетинга. Данные по данному потенциалу представим в таблице 10 , где укажем взвешенные оценки на исследуемых предприятиях и максимальную оценку по данным показателям. 


\begin{tabular}{|c|c|c|c|c|c|c|}
\hline Impact Factor: & $\begin{array}{l}\text { ISRA (India) } \\
\text { ISI (Dubai, UAE } \\
\text { GIF (Australia) } \\
\text { JIF }\end{array}$ & $\begin{array}{l}=1.344 \\
=0.829 \\
=0.564 \\
=1.500\end{array}$ & $\begin{array}{l}\text { SIS (USA) } \\
\text { PИНЦ (Russia) } \\
\text { ESJI (KZ) } \\
\text { SJIF (Morocco) }\end{array}$ & $\begin{array}{l}=0.912 \\
=0.207 \\
=4.102 \\
=\mathbf{2 . 0 3 1}\end{array}$ & $\begin{array}{l}\text { ICV (Poland) } \\
\text { PIF (India) } \\
\text { IBI (India) }\end{array}$ & $\begin{array}{l}=6.630 \\
=1.940 \\
=4.260\end{array}$ \\
\hline
\end{tabular}

Оценка конкурентоспособности предприятий.

Таблица 9

\begin{tabular}{|c|c|c|c|c|c|c|c|c|}
\hline \multirow[t]{2}{*}{$\begin{array}{l}\text { Факторы } \\
\text { конкурентоспособно } \\
\text { сти предприятия }\end{array}$} & \multirow[t]{2}{*}{ Показатели } & \multirow{2}{*}{ 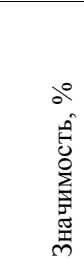 } & \multicolumn{2}{|c|}{ Значения } & \multicolumn{2}{|c|}{$\begin{array}{l}\text { Безразмерные } \\
\text { оценки } \\
\text { показателей } \\
\text { конкурентоспосо } \\
\text { бности } \\
\text { предприятия } \\
\end{array}$} & \multicolumn{2}{|c|}{$\begin{array}{l}\text { Взвешенные } \\
\text { оценки } \\
\text { показателей } \\
\text { конкурентоспосо } \\
\text { бности }\end{array}$} \\
\hline & & & $\begin{array}{l}\text { ООО } \\
\text { Леонов }\end{array}$ & $\begin{array}{l}\text { ЗАО } \\
\text { Донобувь }\end{array}$ & $\begin{array}{l}\text { ООО } \\
\text { Леонов }\end{array}$ & $\begin{array}{l}\text { ЗАО } \\
\text { Донобувь }\end{array}$ & $\begin{array}{l}\text { ООО } \\
\text { Леонов }\end{array}$ & $\begin{array}{l}\text { ЗАО Дон- } \\
\text { обувь }\end{array}$ \\
\hline 1 & 2 & 3 & 4 & 5 & 6 & 7 & 8 & 9 \\
\hline $\begin{array}{l}\text { 1.Конкуренто- } \\
\text { способность товара }\end{array}$ & $\begin{array}{l}\text { Средневзвешенная } \\
\text { по товарному } \\
\text { ассортименту } \\
\text { конкурентоспособн } \\
\text { ость товара, балл }\end{array}$ & 40 & 3,05 & 3,49 & 0,61 & 0,69 & 24,4 & 27,9 \\
\hline \multirow[t]{4}{*}{$\begin{array}{l}\text { 2.Эффективность } \\
\text { маркетинга }\end{array}$} & $\begin{array}{l}\text { Оценка уровня } \\
\text { партнерских } \\
\text { отношений } \\
\text { заинтересованными } \\
\text { сторонами } \\
\text { предприятия, балл } \\
\end{array}$ & 10 & 2,85 & 3,05 & 0,71 & 0,76 & 7,10 & 7,60 \\
\hline & \begin{tabular}{ll}
\multicolumn{3}{l}{ Превышение } & \\
допустимого уровня \\
запасов & гот. \\
продукции, \% & \\
\end{tabular} & 3 & 66,50 & 28,80 & 0,34 & 1,00 & 1,02 & 3,00 \\
\hline & $\begin{array}{l}\text { Доля предприятия } \\
\text { на рынке, \% }\end{array}$ & 3 & 3,00 & 7,30 & 0,08 & 0,20 & 0,24 & 0,60 \\
\hline & $\begin{array}{l}\text { Темп роста объема } \\
\text { продаж, \% }\end{array}$ & 3 & 221,00 & 198,00 & 0,89 & 0,80 & 2,67 & 2,40 \\
\hline \multirow[t]{2}{*}{$\begin{array}{l}\text { 3. Качество } \\
\text { менеджмента }\end{array}$} & $\begin{array}{l}\text { Доходность } \\
\text { инвестиций }\end{array}$ & 3 & 0,85 & 4,02 & 0,08 & 0,39 & 0,24 & 1,17 \\
\hline & $\begin{array}{l}\text { Рентабельность } \\
\text { совокупных } \\
\text { активов, } \% \\
\end{array}$ & 3 & 10,90 & 43,90 & 0,17 & 0,53 & 0,51 & 1,59 \\
\hline \multirow[t]{3}{*}{$\begin{array}{l}\text { 4. Финансовое } \\
\text { состояние } \\
\text { предприятия }\end{array}$} & $\begin{array}{l}\text { Коэффициент обесп. } \\
\text { собственными } \\
\text { оборотн. средствами } \\
(0,2)\end{array}$ & 3 & 0,19 & 0,76 & 0,95 & 3,80 & 2,85 & 11,4 \\
\hline & $\begin{array}{l}\text { Коэффициент } \\
\text { текущей } \\
\text { ликвидности }(\square 1,3)\end{array}$ & 3 & 1,46 & 4,16 & 0,26 & 0,79 & 0,78 & 2,37 \\
\hline & $\begin{array}{l}\text { Затраты на } 1 \text { руб. } \\
\text { реализ. Продукции }\end{array}$ & 3 & 0,69 & 0,53 & 0,86 & 1,00 & 2,58 & 3,00 \\
\hline \multirow[t]{3}{*}{$\begin{array}{l}\text { 5.Уровень } \\
\text { организации } \\
\text { производств }\end{array}$} & $\begin{array}{l}\text { Коэффициент } \\
\text { использования } \\
\text { производственных } \\
\text { мощностей }\end{array}$ & 2 & 0,83 & 0,95 & 0,87 & 1,00 & 1,74 & 2,00 \\
\hline & $\begin{array}{l}\text { Производительност } \\
\text { ь труда }\end{array}$ & 2 & 48,19 & 60,22 & 0,64 & 0,80 & 1,28 & 1,60 \\
\hline & $\begin{array}{l}\text { Износ осн. средств, } \\
\%\end{array}$ & 2 & 26,00 & 47,00 & 0,38 & 0,21 & 0,76 & 0,42 \\
\hline \multirow[t]{2}{*}{$\begin{array}{l}\text { 6.Эффективность } \\
\text { МТО }\end{array}$} & $\begin{array}{l}\text { Оценка связей с } \\
\text { поставщиками, балл }\end{array}$ & 3 & 7,28 & 7,99 & 0,73 & 0,80 & 2,18 & 2,40 \\
\hline & $\begin{array}{l}\text { Материалоотдача, } \\
\text { руб./руб. }\end{array}$ & 3 & 20,45 & 13,48 & 0,13 & 0,12 & 0,39 & 0,36 \\
\hline $\begin{array}{l}\text { 7.Активность } \\
\text { инновац. Деят-сти }\end{array}$ & $\begin{array}{l}\text { Доля } \\
\text { инновационных } \\
\text { товаров, \% } \\
\end{array}$ & 8 & 1,30 & 0,13 & 1,00 & 0,10 & 8,00 & 0,80 \\
\hline $\begin{array}{l}\text { 8.Конкурентоспосо } \\
\text { бность персонала }\end{array}$ & $\begin{array}{lr}\text { Коэффициент } \\
\text { опережения роста } \\
\text { производительности } \\
\text { труда } \\
\text { отношению к росту }\end{array}$ & 3 & 2,06 & 1,56 & 0,95 & 0,72 & 2,85 & 2,16 \\
\hline
\end{tabular}




\section{Impact Factor:}

\begin{tabular}{lr|lr} 
ISRA $($ India $)$ & $=\mathbf{1 . 3 4 4}$ & SIS $($ USA) & $=\mathbf{0 . 9 1 2}$ \\
ISI $($ Dubai, UAE) $=\mathbf{0 . 8 2 9}$ & PИНЦ (Russia) $=\mathbf{0 . 2 0 7}$ \\
GIF (Australia) $=\mathbf{0 . 5 6 4}$ & ESJI (KZ) & $=\mathbf{4 . 1 0 2}$ \\
JIF & $=\mathbf{1 . 5 0 0}$ & SJIF $($ Morocco $)=\mathbf{2 . 0 3 1}$
\end{tabular}

\begin{tabular}{|l|l|l|l|l|l|l|l|l|l|}
\hline \hline & заработной платы & & & & & & & \\
\cline { 2 - 9 } & $\begin{array}{l}\text { Коэффициент } \\
\text { текучести кадров, \% }\end{array}$ & 3 & 7,00 & 6,00 & 0,02 & 0,03 & 0,06 & 0,09 \\
\hline & $\begin{array}{l}\text { Всего максимальная } \\
\text { оценка значимости }\end{array}$ & 10 & - & - & - & - & 59,6 & 70,8 \\
\hline
\end{tabular}

Как видно из ниже представленной таблицы 10, отклонение по потенциалу эффективность маркетинга в ООО «Леонов» составляет -7,97, в ЗАО «Донобувь» -5,4. Наибольшее влияние на данное отклонение оказывает показатель уровня и качества партнерских отношений с заинтересованными сторонами, поэтому для повышения эффективности маркетинговой деятельности исследуемым предприятиям следует налаживать и развивать взаимоотношения с партнерами.

Таблица 10

Анализ эффективности использования маркетингового потенциала.

\begin{tabular}{|c|c|c|c|c|c|c|}
\hline \multirow[t]{2}{*}{$\begin{array}{l}\text { Показатели оценки } \\
\text { эффективности } \\
\text { маркетинга }\end{array}$} & \multirow{2}{*}{ 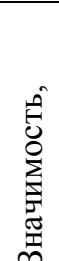 } & \multicolumn{2}{|c|}{$\begin{array}{l}\text { Взвешенные оценки } \\
\text { показателей } \\
\text { конкурентоспособности }\end{array}$} & \multirow{2}{*}{$\begin{array}{l}\text { Максимальная } \\
\text { взвешенная } \\
\text { оценка }\end{array}$} & \multicolumn{2}{|c|}{$\begin{array}{l}\text { Отклонение взвешенной } \\
\text { оценки от максимальной }\end{array}$} \\
\hline & & ООО Леонов & $\begin{array}{l}\text { ЗАО } \\
\text { Донобувь }\end{array}$ & & ООО Леонов & $\begin{array}{l}\text { ЗАО } \\
\text { Донобувь }\end{array}$ \\
\hline $\begin{array}{l}\text { Оценка уровня } \\
\text { партнерских } \\
\text { отношений } \\
\text { заинтересованными } \\
\text { сторонами } \\
\text { предприятия, балл }\end{array}$ & 1 & 7,1 & 7,6 & 10 & $-2,9$ & $-2,4$ \\
\hline $\begin{array}{l}\text { Превышение } \\
\text { допустимого } \\
\text { уровня запасов гот. } \\
\text { продукции, \% } \\
\end{array}$ & 3 & 1,02 & 3 & 3 & $-1,98$ & 0 \\
\hline $\begin{array}{l}\text { Доля } \text { предприятия } \\
\text { на рынке, \% }\end{array}$ & 3 & 0,24 & 0,6 & 3 & $-2,76$ & $-2,4$ \\
\hline $\begin{array}{l}\text { Темп роста объема } \\
\text { продаж, \% }\end{array}$ & 3 & 2,67 & 2,4 & 3 & $-0,33$ & $-0,6$ \\
\hline Итого & 1 & 11,03 & 13,6 & 19 & $-7,97$ & $-5,4$ \\
\hline
\end{tabular}

Итак, при оценке конкурентоспособности исследуемых предприятий выявлено, что уровень конкурентоспособности ООО «Леонов», ЗАО «Донобувь» - средний $(59,65 \%$ и $70,88 \%$ соответственно). Одним из важных факторов, который оказывает влияние на оценку конкурентоспособности - эффективность маркетинга. Из проведенного анализа видно, что отклонение по данному потенциалу составляет в ООО «Леонов» - 7,97, ЗАО «Донобувь»-5,4. В целях повышения эффективности маркетинга предприятиям следует внедрить концепцию заинтересованных сторон, которая будет способствовать развитию взаимоотношений с партнерами.

$$
\text { Итак, для }
$$

конкурентоспособности предприятий на основе теории партнерских отношений предлагается внедрить механизм формирования взаимодействия с заинтересованными сторонами.

Таким образом, теория партнерских отношений становится актуальной на сегодняшний день, поэтому с учетом значимости данного фактора разработана методика оценки конкурентоспособности предприятия с учетом новой парадигмы - теории партнерских отношений. Разработанная методика оценки и анализа конкурентоспособности предприятия на основе теории партнерских отношений, позволяет провести углубленный анализ конкурентоспособности предприятий с учетом важного фактора конкурентных преимуществ в условиях сетевой экономики - качества и уровня развития партнерских отношений.

В качестве основных уникальных аспектов формирования конкурентного преимущества предприятий на базе ориентированного на 
теорию партнерских отношений можно выделить:

создание и перманентное расширение базы данных ключевых партнеров; формирование необходимой технической базы (компьютеры, периферийные устройства и программное обеспечение);

организация деятельности подразделения и отдельных менеджеров по управлению взаимоотнотениями с заинтересованными сторонами;

разработка и корректировка планов по взаимодействию с ключевыми партнерами, с учетом их деловых и личностных особенностей; регулярное проведение аудита деятельности менеджеров по управлению взаимоотношениями с партнерами в разрезе оценки следуюших показателей:

$\square \quad$ количество встреч с партнерами, количество подготовленных коммерческих предложений, количество заключенных договоров, динамика объемов поставок продукиии приходящихся на каждого партнера; регулярное

проведение маркетинговых исследований в рамках партнерских отношений $c$ целью выявления изменений в структуре $u$ характере предпочтений при выборе партнеров.

Таким образом, вышеперечисленные аспекты, при должном уровне их проработки, могут позволить предприятию сформировать уникальное конкурентное преимущество систему взаимоотношений с заинтересованными сторонами.

Наполнение технологических процессов по производству конкурентоспособной и востребованной обуви для потребителей регионов ЮФО и СКФО является затратным. Использование универсального и многофункционального оборудования формирует технологический процесс таким образом, что позволяет изготавливать весь ассортиментный ряд обуви высокого качества и с разной ценовой нишей, создавая ей приоритеты при реализации [4-5].

Хотелось бы отметить еще одно несомненное достоинство выполненных авторами исследований тот факт, что кроме предложений для производителей использовать универсальное и многофункциональное оборудование для сборки заготовок верха обуви и формования заготовок верха на колодке, предлагается использовать технологию прямого литья низа на обуви и такое оборудование, которое способно как раз обеспечить производство востребованного ассортиментного ряда обуви как по видам, так по родам и создают предпосылки высокой эффективности самого производства и удовлетворить спрос не только потребителей регионов ЮФО и СКФО, но отечественных и зарубежных покупателей.

Партнерские отношения можно разделить на две группы: внешние и внутренние. К внешним относятся: покупатели, поставщики, конкуренты, государственные учреждения и организации, органы регионального и муниципального управления, финансовые посредники.

Покупатели. Стратегия и тактика работы с важными покупателями включает в себя совместные заседания для определения движущих сил изменения бизнеса, обоюдные усилия по разработке продукции и рынка, увеличению коммуникативных связей, использованию общих площадей и совместные программы обучения и обслуживания. Укрепление связей с покупателями часто дает значительную выгоду [6-7]

Внутренние партнеры включают менеджеров, служащих, владельцев и совет директоров или правление, в котором представлены менеджеры и владельцы. Один из самых значимых внутренних партнёров управляющий высшего ранга.

Таким образом, успешность предприятия определяется степенью удовлетворения интересов заинтересованных лиц, поэтому для повышения конкурентоспособности и эффективности деятельности, предприятие должно учитывать не только свои интересы, но и интересы заинтересованных сторон.

Поэтому с учетом рассмотренных методологических основ конкурентоспособности предприятия, предлагается методика оценки и анализа конкурентоспособности предприятия на основе теории заинтересованных сторон.

Этап 1. Выбор показателей оценки факторов конкурентоспособности предприятия.

Для каждого фактора можно определить систему показателей на основе анализа научной литературы (таблица 11).

Итак, с учетом проведенного анализа системы показателей оценки конкурентного потенциала предприятия, можно предложить следующую система показателей оценки внутренних факторов конкурентоспособности предприятия (таблица 12). 


\begin{tabular}{|c|c|c|c|c|c|c|}
\hline Impact Factor: & $\begin{array}{l}\text { ISRA (India) } \\
\text { ISI (Dubai, UAE } \\
\text { GIF (Australia) } \\
\text { JIF }\end{array}$ & $\begin{array}{l}=1.344 \\
=0.829 \\
=0.564 \\
=1.500\end{array}$ & $\begin{array}{l}\text { SIS (USA) } \\
\text { PИНЦ (Russia) } \\
\text { ESJI (KZ) } \\
\text { SJIF (Morocco) }\end{array}$ & $\begin{array}{l}=0.912 \\
=0.207 \\
=4.102 \\
=2.031\end{array}$ & $\begin{array}{l}\text { ICV (Poland) } \\
\text { PIF (India) } \\
\text { IBI (India) }\end{array}$ & $\begin{array}{l}=6.630 \\
=1.940 \\
=4.260\end{array}$ \\
\hline
\end{tabular}

Таблица 11

Система показателей оценки конкурентного потенциала обувных предприятия.

\begin{tabular}{|c|c|}
\hline $\begin{array}{l}\text { Факторы конкурентного } \\
\text { потенциала }\end{array}$ & Показатели оценки \\
\hline 1 & 2 \\
\hline \multirow{6}{*}{$\begin{array}{l}\text { 1.Эффективность } \\
\text { маркетинга }\end{array}$} & Соотношение качества товара и издержек его производства и маркетинга \\
\hline & Темп роста товарной продукции \\
\hline & Рост объемов продаж и прибыли \\
\hline & Прибыльность \\
\hline & Доля на рынке, имидж \\
\hline & Качество партнерских отношений \\
\hline \multirow[t]{2}{*}{$\begin{array}{ll}2 . & \text { Качество } \\
\text { менеджмента } & \end{array}$} & $\begin{array}{l}\text { Доходность совокупных активов, доходность собственного капитала; } \\
\text { доходность инвестиций }\end{array}$ \\
\hline & $\begin{array}{l}\text { Чистая прибыль на } 1 \text { руб. объема реализации; прибыль от реализации } \\
\text { продукции на } 1 \text { руб. объема реализации; прибыль отч. периода на } 1 \text { руб. } \\
\text { объема реализации }\end{array}$ \\
\hline $\begin{array}{l}\text { 3.Финансовое состояние } \\
\text { предприятия }\end{array}$ & $\begin{array}{l}\text { Коэффициент обеспеченности собственными средствами; коэффициент } \\
\text { текущей ликвидности; коэффициент покрытия, коэффициент автономии, } \\
\text { индекс постоянного актива, общая рентабельность предприятия, } \\
\text { рентабельность собственного капитала, рентабельность продукции }\end{array}$ \\
\hline \multirow{3}{*}{$\begin{array}{l}\text { 4. Уровень организации } \\
\text { производства }\end{array}$} & 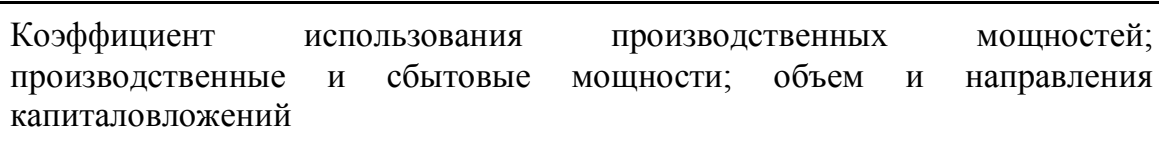 \\
\hline & $\begin{array}{l}\text { Доля сертифицированной продукции в соответствии с международными } \\
\text { стандартами серии ИСО } 9000\end{array}$ \\
\hline & Износ ОПФ, рост производительности труда \\
\hline 5. Эффективность МТО & $\begin{array}{l}\text { Качество и цены поставляемых материалов. Материалоотдача, } \\
\text { товарооборот, допускающий прямые связи; коэффициент равномерности } \\
\text { поступления товаров; рентабельность расходов по сделке; рентабельность } \\
\text { закупки товара }\end{array}$ \\
\hline \multirow{3}{*}{$\begin{array}{l}6 . \quad \text { Активность } \\
\text { инновационной } \\
\text { деятельности }\end{array}$} & Ежегодные расходы на НИОКР, число патентов на изобретения \\
\hline & $\begin{array}{l}\text { Доля инновационных товаров, удельный вес экспорта продукции, число } \\
\text { созданных передовых технологий }\end{array}$ \\
\hline & $\begin{array}{l}\text { Объем отгруженной инновационной продукции (услуг), число } \\
\text { запатентованных технологий, количество технологий, обладающих } \\
\text { патентной чистотой, расходы на инновации, количество приобретенных и } \\
\text { переданных новых технологий, программных средств }\end{array}$ \\
\hline $\begin{array}{l}\text { 7.Конкурентоспособность } \\
\text { персонала }\end{array}$ & $\begin{array}{l}\text { Коэффициент текучести } \quad \text { кадров, коэффициент опережения } \\
\text { производительности труда по отношению к заработной плате, } \\
\text { образовательный уровень рабочей силы, уровень профессиональной } \\
\text { квалификации рабочих }\end{array}$ \\
\hline
\end{tabular}

Этап 2. Определение значимости показателей в общей оценке конкурентоспособности. Значимость показателей оценки каждого фактора конкурентного потенциала представлены в таблице 12. 


\begin{tabular}{l|lr|ll|ll} 
& ISRA (India) & $=\mathbf{1 . 3 4 4}$ & SIS (USA) & $=\mathbf{0 . 9 1 2}$ & ICV (Poland) & $=\mathbf{6 . 6 3 0}$ \\
Impact Factor: & ISI (Dubai, UAE) $=\mathbf{0 . 8 2 9}$ & PUHЦ (Russia) $=\mathbf{0 . 2 0 7}$ & PIF (India) & $=\mathbf{1 . 9 4 0}$ \\
& GIF (Australia) & $\mathbf{0 . 5 6 4}$ & ESJI (KZ) & $=4.102$ & IBI (India) & $=\mathbf{4 . 2 6 0}$ \\
& JIF & $=\mathbf{1 . 5 0 0}$ & SJIF (Morocco) & $=\mathbf{2 . 0 3 1}$ & & \\
\hline
\end{tabular}

Таблица 12

Рекомендуемая система показателей оценки конкурентоспособности предприятия и их значимость

\begin{tabular}{|c|c|c|}
\hline $\begin{array}{l}\text { Факторы } \\
\text { конкурентоспособности } \\
\text { предприятия }\end{array}$ & Показатели & $\begin{array}{l}\text { Значимость, } \\
\%\end{array}$ \\
\hline 1 & 2 & 3 \\
\hline $\begin{array}{l}\text { 1.Конкурентоспо- } \\
\text { собность товара }\end{array}$ & $\begin{array}{l}\text { Средневзвешенная по товарному ассортименту } \\
\text { конкурентоспособность товара }\end{array}$ & 40 \\
\hline \multirow[t]{5}{*}{$\begin{array}{l}\text { 2.Эффективность } \\
\text { маркетинга }\end{array}$} & $\begin{array}{l}\begin{array}{l}\text { Превышение } \\
\text { продукции }\end{array} \\
\end{array}$ & 3 \\
\hline & Доля предприятия на рынке & 3 \\
\hline & Темп роста объема продаж & 3 \\
\hline & 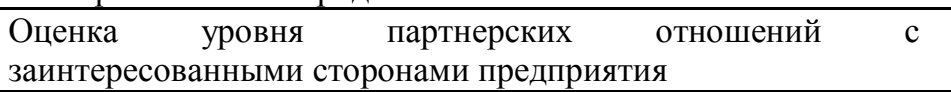 & 10 \\
\hline & Итого & 19 \\
\hline \multirow[t]{3}{*}{ 3. Качество менеджмента } & Доходность инвестиций & 3 \\
\hline & Рентабельность совокупных активов & 3 \\
\hline & Итого & 6 \\
\hline \multirow[t]{4}{*}{$\begin{array}{l}\text { 4. Финансовое состояние } \\
\text { предприятия }\end{array}$} & $\begin{array}{l}\text { Коэффициент обеспеченности собственными оборотными } \\
\text { средствами }\end{array}$ & 3 \\
\hline & Коэффициент текущей ликвидности & 3 \\
\hline & Затраты на 1 руб. реализованной продукции & 3 \\
\hline & Итого & 9 \\
\hline \multirow{4}{*}{$\begin{array}{l}\text { 5.Уровень организации } \\
\text { производства }\end{array}$} & Коэффициент использования производственных мощностей & 2 \\
\hline & Производительность труда & 2 \\
\hline & Износ основных средств & 2 \\
\hline & Итого & 6 \\
\hline \multirow[t]{3}{*}{ 6. Эффективность МТО } & Снижение уровня материалоемкости & 3 \\
\hline & Материалоотдача & 3 \\
\hline & Итого & 6 \\
\hline \multirow{3}{*}{$\begin{array}{l}7 . \quad \text { Активность } \\
\text { инновационной } \\
\text { деятельности }\end{array}$} & Доля инновационных товаров & 4 \\
\hline & Затраты на инновации & 4 \\
\hline & Итого & 8 \\
\hline \multirow[t]{5}{*}{$\begin{array}{l}\text { 8.Конкурентоспособность } \\
\text { персонала }\end{array}$} & $\begin{array}{l}\text { Коэффициент опережения роста производительности труда } \\
\text { по отношению к росту заработной платы }\end{array}$ & 3 \\
\hline & Коэффициент текучести кадров & 3 \\
\hline & Итого & 6 \\
\hline & Итого значимость конкурентного потенциала & 60 \\
\hline & Всего максимальная оценка значимости & 100 \\
\hline
\end{tabular}

\section{Заключение}

Экономический смысл полученной обобщающей оценки конкурентоспособности состоит в том, что она с одной стороны показывает степень удовлетворенности товаром, a c другой - степень использования конкурентного потенциала самого предприятия.

Предложенная методика оценки и анализа конкурентоспособности предприятия, в отличие от существующих, во-первых, учитывает специфику отрасли «легкая промышленность», во-вторых, снижает субъективный фактор в оценке, в-третьих, позволяет провести углубленный анализ, благодаря предложенным направлениям и показателям анализа конкурентоспособности предприятий. 


\begin{tabular}{l|lr|ll|ll} 
& ISRA (India) & $=\mathbf{1 . 3 4 4}$ & SIS (USA) & $=\mathbf{0 . 9 1 2}$ & ICV (Poland) & $=\mathbf{6 . 6 3 0}$ \\
Impact Factor: & ISI (Dubai, UAE) $=\mathbf{0 . 8 2 9}$ & PUHL (Russia) $=\mathbf{0 . 2 0 7}$ & PIF (India) & $=\mathbf{1 . 9 4 0}$ \\
& GIF (Australia) & $\mathbf{0 . 5 6 4}$ & ESJI (KZ) & $=\mathbf{4 . 1 0 2}$ & IBI (India) & $\mathbf{4 . 2 6 0}$ \\
& JIF & $=\mathbf{1 . 5 0 0}$ & SJIF (Morocco) & $=\mathbf{2 . 0 3 1}$ & & \\
\hline
\end{tabular}

\section{References:}

1. (2012) Managing production of competitive products in demand: / V. T. Prokhorov [et al.]; under the General editorship of doctor of technical Sciences, Professor V. T. Prokhorov. Novocherkassk: yurgtu (NPI), 2012. - 280 p.

2. (2014) On finding funds impact the cash flows on the performance of footwear enterprises in the regions of SFD and NCFD/ Yu. M. Train, S. Yu. Polukhina, T. M. Osina, E. V., Kononenko, E. N. Meleshko// Innovative development of light and textile industry" (INTEX-2014): abstracts of all-Russian scientific student conference. - M.: FGBOU VPO "MSUDT", 2014. - p. 116.

3. (2014) The quality revolution: through the ad or through a quality real: monograph V. T. Prokhorov [et al.]; under the General editorship of doctor of technical Sciences, Professor V. T. Prokhorov; VoIP (branch) of DSTU. Novocherkassk: URGU (NPI), 2014. - 384 p.

4. (2010) Modern approaches to ensure demand for the products of Shoe enterprises of the southern Federal District the monograph [Text] [etc.]/ V. T. Prokhorov, etc.; under the General editorship of Professor V. T. Prokhorov - Mine:
Publishing house GOU VPO yurgues, 2010. p. $29-137$

5. (2014) The regional economy: development trends: the monograph A. N. Biryukov, E. V. Borilo, O. I., Glushchenko, T. M. Aspen Voronezh : vgpu, 2014.- 159 p.

6. Getmanova, E. F., S. Y. Korablina V. T. Prokhorov, T. M., ASP, N. In. Tikhonova, I. S. (2016) Shrivel import Substitution footwear at the expense of informed decision assortment policy to ensure consumers popular shoes// II international scientific and practical conference "Models of innovative development of textile and light industry based on the integration of University science and industry. Educationscience-production" : collection of articles. 2325 March 2016; M-in the way. and science of Russia, Kazan. NAT. issled. tekhnol. Univ. of Illinois - Kazan : Publishing house of KAZAN state technical University, 2016. - p. 335-341

7. D. V. Reva, Y. S. Korablina V. T. Prokhorov, I. G. Narozhnaya, N. Tikhonov (2016) Formation of import-substituting assortment of shoes for domestic markets. - p. 364-371. 